Ciência Florestal, Santa Maria, v. 23, n. 2, p. 491-502, abr.-jun., 2013

ISSN 0103-9954

\title{
POTENCIAL ENERGÉTICO DA MADEIRA DE ESPÉCIES ORIUNDAS DE PLANO DE MANEJO FLORESTAL NO ESTADO DO RIO GRANDE DO NORTE
}

\section{ENERGY POTENTIAL OF SPECIES FROM FOREST MANAGEMENT PLAN FOR THE RIO GRANDE DO NORTE STATE}

\section{Rosimeire Cavalcante dos Santos ${ }^{1}$ Angélica de Cássia Oliveira Carneiro ${ }^{2}$ Alexandre Santos Pimenta ${ }^{3}$ Renato Vinícius Oliveira Castro ${ }^{4}$ Itaragil Venâncio Marinho ${ }^{5}$ Paulo Fernando Trugilho ${ }^{6}$ Isabel Cristina Nogueira Alves ${ }^{7}$ Ana Flávia Neves Mendes Castro ${ }^{8}$}

\section{RESUMO}

O objetivo do trabalho foi avaliar o potencial energético das madeiras de espécies sob plano de manejo florestal provenientes da região do Seridó, no estado do Rio Grande do Norte. Utilizou-se na pesquisa, madeiras das espécies Jurema-preta, Pereiro, Marmeleiro, Catingueira, Mororó, Imburana, Jurema-branca e Mofumbo, aos 20 anos de idade, originadas da fazenda Dominga no município de Caicó/RN. Foram realizadas na madeira, as análises da densidade básica, teores de materiais voláteis, cinzas e carbono fixo, poder calorífico superior, composição química elementar e relações carbono/nitrogênio $(\mathrm{C} / \mathrm{N})$ e carbono/ hidrogênio $(\mathrm{C} / \mathrm{H})$. Adicionalmente, estimou-se a quantidade de energia produzida em kW.h.m $\mathrm{m}^{-3} \mathrm{e}$ em $\mathrm{kW} \cdot \mathrm{h} \cdot \mathrm{ha}^{-1}$ para todas as espécies. O experimento foi realizado segundo um delineamento inteiramente casualizado com oito tratamentos (espécies), quatro repetições (árvores-amostra), totalizando 32 unidades amostrais. Houve diferença significativa, a $5 \%$ de significância, entre os tratamentos para todas as variáveis analisadas, exceto para a porcentagem de hidrogênio e relação $\mathrm{C} / \mathrm{H}$. Conclui-se que a madeira de Mororó apresenta alto potencial energético, e juntamente com a Jurema-preta, maior geração de energia por $\mathrm{m}^{3}$, além de proporcionar maior economia para uma mesma produtividade. O potencial energético da madeira de Jurema-preta se destaca entre as espécies estudadas. A madeira de Pereiro se destaca na produção de energia por hectare. As madeiras de Jurema-branca e Marmeleiro são indicadas como potenciais para queima direta. A madeira de Imburana não é recomendada para a geração de energia.

Palavras-chave: potencial energético; semiárido nordestino; qualidade da madeira; propriedades da madeira.

\section{ABSTRACT}

The objective was to evaluate the energy potential of woods of species under forest management

1. Engenheira Florestal, $\mathrm{Dr}^{\mathrm{a}}$., Professora da Unidade Acadêmica Especializada em Ciências Agrárias, Escola Agrícola de Jundiaí, Universidade Federal do Rio Grande do Norte, CEP 59078-970, Natal (RN). meire_caico@yahoo.com.br

2. Engenheira Florestal, $\operatorname{Dr}^{\mathrm{a}}$., Professora do Departamento de Ciência Florestal, Universidade Federal de Viçosa, CEP 36570-000, Viçosa (MG). cassiacarneiro@ufv.br

3. Engenheiro Florestal, Dr., da Unidade Acadêmica Especializada em Ciências Agrárias, Escola Agrícola de Jundiaí, Universidade Federal do Rio Grande do Norte, CEP 59078-970, Natal (RN). alexandre_spimenta@hotmail.com

4. Engenheiro Florestal, Doutor em Ciência Florestal, Professor Adjunto da UnB, CEP 70910-900, Brasília (DF), castrorvo@ymail.com

5. Engenheiro Florestal, Pesquisador da Emater/PB - SOS Sertão. Rua Zuza Cabral, 18, CEP 58705-220, Patos (PB). ivmarinho@bol.com.br

6. Engenheiro Florestal, Dr., Professor do Departamento de Ciências Florestais, Universidade Federal de Lavras, CEP 37200-000, Lavras (MG). trugilho@ufla.br

7. Engenheira Florestal, MSc., Doutoranda em Ciências Florestais, Universidade Federal de Lavras, CEP 37200-000, Lavras (MG). isabel.alves@posgrad.ufla.br

8. Engenheira Florestal, MSc., Doutoranda em Ciência Florestal, Universidade Federal de Viçosa, CEP 36570-000, Viçosa (MG).mendesafn@hotmail.com

Recebido para publicação em 12/05/2011 e aceito em 2/09/2011 
plan from Seridó region in the Rio Grande do Norte state. It was used the wood species Jurema Preta, Pereiro, Marmeleiro, Catingueira, Mororó, Imburana, Jurema Branca and Mofumbo, at 20 years old, originated from the Dominga's farm in the Caicó/RN municipality. The density, the content of volatiles, the ash and fixed carbon, calorific value, elemental composition and carbon/nitrogen $(\mathrm{C} / \mathrm{N})$ and carbon/ hydrogen $(\mathrm{C} / \mathrm{H})$ analysis were carried out in the wood. Additionally, the amount of energy produced in $\mathrm{kW} . h . \mathrm{m}^{-3}$ and kW.h.ha ${ }^{-1}$ for all species was estimated. The experiment was conducted in a completely randomized design with eight treatments (species), four replicates (sample trees), adding up to 32 sampling units. There were significant differences, at $5 \%$ significance between treatments for all variables, except for hydrogen percentage and $\mathrm{C} / \mathrm{H}$ ratio. It was concluded that Mororó's wood shows high energy potential, and along with Jurema Preta, presents higher energy generation per $\mathrm{m}^{3}$, and provides greater economy for the same productivity. The energy potential Jurema Preta wood's stands out among the species. Pereiro's wood stands for energy production per hectare. Marmeleiro and Jurema Branca's woods are indicated as direct burning potential and Imburana's wood is not recommended for power generation.

Keywords: energy potential; northeast semiarid; wood quality; energetic properties.

\section{INTRODUÇÃO}

A avaliação da qualidade da madeira para energia é de extrema importância quando se objetiva uma melhor conversão energética da mesma, seja na queima direta ou na produção de carvão vegetal com alto rendimento e baixo custo. Pois, uma vez conhecendo as características da madeira, pode-se otimizar o potencial das espécies destinando-se àquelas que possui, dentre outra características, maior quantidade de energia por unidade de massa para usos específicos.

Um fator limitante relacionado à sua utilização com maior eficiência é a falta de conhecimento das suas propriedades energéticas e a forma inadequada de sua utilização, uma vez que a eficiência de conversão sofre grande influência da madeira. Além da produtividade, características como densidade básica, teores de carbono fixo, materiais voláteis e cinzas, como também a composição elementar e o poder calorífico, estão entre os principais critérios de seleção da madeira para essa atividade.

No estado do Rio Grande do Norte, segundo dados da secretaria extraordinária de energia do estado (IBGE, 2006), do total de energia produzido, $15,7 \%$, foram consumidos diretamente como energia primária.

Um relatório técnico, publicado pelo IBAMA (1992) citado por ZÁKIA (1992), ressalta que, em 1991 , aproximadamente $69,3 \%$ da energia consumida no Rio Grande do Norte foi originada da vegetação nativa, fato esse que representa um consumo de lenha anual de 830.722 toneladas.

É sabido que não há desmatamentos legalizados em quantidade suficiente no Estado do RN, o que faz com que boa parte da lenha consumida pelos setores doméstico, comercial e industrial seja de pro- cedência e, especialmente, com características tecnológicas igualmente desconhecidas.

Dessa forma, o estudo da potencialidade energética de espécies em áreas sob manejo florestal irá amenizar essa realidade buscando solucionar problemas por meio de alternativas que possam minimizar impactos e assegurar a sustentabilidade do uso da lenha e do carvão vegetal perante outros combustíveis fósseis. Assim, será possível fortalecer as indústrias, bem como contribuir para o meio ambiente e desenvolvimento econômico e social do estado do Rio Grande do Norte.

Assim, considera-se indispensável romper o ciclo entre o estudo de potencialidades sem basear-se em áreas que são exploradas de forma planejada, e desse modo, proporcionar conhecimento tecnológico da madeira com significativos benefícios para o desenvolvimento socioeconômico e ambiental do nordeste e, especialmente, do estado do Rio Grande do Norte.

Dentro desse contexto, o objetivo geral desse trabalho foi avaliar o potencial energético de espécies sob plano de manejo florestal provenientes da região do Seridó no semiárido nordestino no estado do Rio Grande do Norte.

\section{MATERIAL E MÉTODO}

O estudo foi realizado com madeiras provenientes de um povoamento com 20 anos de idade, localizado no imóvel rural Fazenda Dominga, município de Caicó, Estado do RN, situado entre as coordenadas geográficas $6^{\circ} 18^{\prime} 55.3^{\prime \prime} \mathrm{S}$ e $36^{\circ} 59^{\prime} 28.8^{\prime \prime}$ $\mathrm{W}$, que compreende uma área total de $2.005,8$ hectares (ha), sendo que desses, 367,9 ha de vegetação nativa de caatinga estão submetidos ao manejo florestal 
madeireiro.

O clima predominante, segundo a classificação de Köppen, é o BSw'h', que se caracteriza como um clima quente e semiárido, com estação chuvosa se atrasando para outono, com pequeno ou nenhum excesso de água, com período seco de 7 a 8 meses, com médias pluviométricas entre 500 e $600 \mathrm{~mm}$ anuais, e temperaturas médias quentes, maiores que $18^{\circ} \mathrm{C}$ em todos os meses (ANA, 2005; IBGE, 2002). O relevo regional está caracterizado pela Depressão Sertaneja com presença de Planaltos (da Borborema) de Escarpas Erosivas (IBGE, 2006), com predominância de Luvissolos Crômicos com afloramentos de rocha, e Solos Litólicos Eutróficos e Podzólicos Vermelho-Amarelo Eutróficos nas áreas serranas da propriedade rural (IBGE, 2001).

A vegetação predominante é caracterizada pela Savana Estépica Arborizada com estratos arbóreo (de árvores baixas providas de acúleos ou espinhos) e gramíneo-lenhoso periódico, com diversas cactáceas e bromeliáceas, e acentuado nível de endemismo, destacando-se os gêneros Aspidosperma, Croton, Mimosa e Spondias, entre outros (IBGE, 2004), ou Caatinga Arbustiva Arbórea Aberta antropizada, podendo se encontrar nas áreas de difícil acesso (de relevo ondulado regionalmente conhecido por "serras"), Caatinga Arbustiva Arbórea Fechada (ANA, 2005).

$\mathrm{O}$ projeto implementado nessa área visa explorar a caatinga T2 (Arbustiva Arbórea Aberta), sob regime de manejo florestal, para produzir 19.404,6 estéreos (st) de lenha por meio da exploração sustentável dos referidos 367,9 ha, com produtividade média de 52,8 estéreos por hectare $\left(\mathrm{st}^{-} \mathrm{ha}^{-1}\right)$, num ciclo de corte de 15 anos, por meio do corte seletivo da vegetação lenhosa em área não contínua. $\mathrm{O}$ material madeireiro refere-se à lenha com destino energético.

As espécies foram selecionadas baseando-se no índice de valor de importância (IVI), expresso no plano de manejo das áreas, realizado pelo Projeto Sustentabilidade Bioenergética Florestal para as Cerâmicas do Vale Carnaúba/RN executado pela Organização Sertaneja dos Amigos da Natureza (SOS Sertão).

Os inventários florestais das áreas foram realizados sob amostragem de 30 parcelas para fins de mensuração dos indivíduos aproveitáveis para a produção de lenha. Com as correções realizadas a partir das recomendações do plano de manejo florestal, foram aproveitadas 11 parcelas, e nessas, foram realizadas as coletas para o estudo da potencialidade energética das espécies, com base na média quadrática dos diâmetros das oito espécies de maior IVI.

A seleção das árvores-amostra foi feita excluindo-se àquelas que, visualmente, apresentavam defeito e também as que estavam sob efeito de bordadura. Foram coletadas 4 árvores, por espécie, totalizando 32 árvores provenientes de 8 espécies. Dessas árvores foram retiradas amostras de madeira com comprimento médio de $71 \mathrm{~cm}$, entre o DAP e a base da árvore (cerca de 30 centímetros acima no nível do solo). A partir dessas, foram retirados discos para realização das seguintes análises na madeira: densidade básica, teores de materiais voláteis, cinzas e carbono fixo, poder calorífico superior e composição química elementar. Além das relações carbono/nitrogênio $(\mathrm{C} / \mathrm{N})$ e carbono/hidrogênio $(\mathrm{C} / \mathrm{H})$.

Foram realizados, adicionalmente, os cálculos para estimação da quantidade de energia produzida em kW.h.m ${ }^{-3}$ e em kW.h.ha $a^{-1}$ para todas as espécies.

As informações gerais sobre as espécies estudadas e os critérios estabelecidos para a amostragem estão apresentados na Tabela 1.

TABELA 1: Espécies estudadas e critérios para amostragem experimental.

TABLE 1: Studied species and criteria for experimental sampling.

\begin{tabular}{llccc}
\hline Nome Vulgar & Nome Científico & $\begin{array}{c}q \\
(\mathrm{~cm})\end{array}$ & $\begin{array}{c}\text { IVI } \\
(\%)\end{array}$ & $\begin{array}{c}\text { Volume } \\
\left(\mathrm{m}^{3} / \mathrm{ha}\right)\end{array}$ \\
\hline Jurema-preta & Mimosa tenuiflora (Willd.) Poiret & 28,4 & 45,75 & 5,88 \\
Pereiro & Aspidosperma pyrifolium Mart & 32,8 & 28,68 & 2,36 \\
Marmeleiro & Croton sonderianus Müll.Arg. & 16,6 & 6,32 & 0,19 \\
Catingueira & Caesalpinia pyramidalis Tul. var. pyramidalis & 31,2 & 4,04 & 0,11 \\
Mororó & Bauhinia cheilantha (Bong.) Steud. & 25,3 & 1,70 & 0,02 \\
Imburana & Commiphora leptophloeos (Mart.) J.B.Gillett & 27,1 & 1,21 & 0,06 \\
Jurema-branca & Piptadenia stipulacea (Benth.) Ducke & 21,4 & 2,18 & 0,05 \\
Mofumbo & Combretum leprosum Mart. & 16,5 & 0,90 & 0,01 \\
\hline
\end{tabular}

Em que: $q$ = diâmetro médio amostrado (cm); IVI = índice de valor de importância (\%). 


\section{Preparo das amostras}

De cada árvore retirou-se um disco, na altura do DAP, com espessura média de $5 \mathrm{~cm}$. Desses, foram retiradas as cascas e obtidas quatro cunhas opostas, passando pela medula. Posteriormente, duas cunhas foram utilizadas para a determinação da densidade básica da madeira e as outras duas para a produção de serragem visando à determinação da análise química imediata, composição elementar e poder calorífico superior da madeira. As análises foram realizadas sob amostragem composta com três repetições por parâmetro estudado.

\section{Determinação da densidade básica}

Os procedimentos utilizados para a análise da densidade básica da madeira estão de acordo com o método de imersão em água, descrito por Vital (1984). Os valores foram calculados a partir da média aritmética das densidades observadas em cada uma das quatro árvores por espécie.

\section{Análise química imediata}

A composição química imediata da madeira foi obtida em amostras moídas e peneiradas a uma granulometria de, aproximadamente, $0,2 \mathrm{~mm}$, seguindo os procedimentos preconizados nas normas ABNT NBR 6923 (ABNT, 1981) e ABNT NBR 8112 (ABNT, 1986), com algumas adaptações, para a determinação dos teores de materiais voláteis, cinzas e carbono fixo, em base seca.

\section{Determinação do poder calorífico superior}

O poder calorífico superior da madeira foi determinado de acordo com a metodologia descrita pela norma da ABNT NBR 8633 (ABNT, 1984), utilizando-se uma bomba calorimétrica adiabática.

As amostras foram classificadas em peneiras de 40/60 mesh. As frações das amostras, retidas na peneira de $60 \mathrm{mesh}$, foram secas em estufa a $103 \pm 2{ }^{\circ} \mathrm{C}$, até peso constante, para a determinação do poder calorífico superior.

\section{Composição química elementar e relações $\mathbf{C} / \mathbf{N}$ e $\mathrm{C} / \mathrm{H}$}

A análise da composição química elementar avaliando as porcentagens de carbono (C), nitrogênio $(\mathrm{N})$, hidrogênio $(\mathrm{H})$, enxofre $(\mathrm{S})$ e oxigênio $(\mathrm{O})$ e as relações $\mathrm{C} / \mathrm{N}$ e $\mathrm{C} / \mathrm{H}$ foi realizada aferindo-se uma massa equivalente a $2,5 \mathrm{mg}( \pm 0,5)$ de serragem seca que foi selecionada em peneiras sobrepostas de 200 e 270 mesh, sendo utilizada a fração que passou nessa última. O equipamento utilizado foi Vario
Micro Cube CHNS-O.

O oxigênio foi quantificado pelo somatório do C, N, H e S decrescido de 100.

$\mathrm{O}$ analisador utiliza como gás de arraste e ignição o hélio e o oxigênio, respectivamente.

\section{Produção de energia}

Para o cálculo da quantidade de energia por $\mathrm{m}^{3}$ obteve-se a massa seca de cada espécie, equivalente a densidade $\left(\mathrm{kg} / \mathrm{m}^{3}\right)$ encontrada em $1 \mathrm{~m}^{3}$ de madeira. $\mathrm{O}$ cálculo da energia por $\mathrm{m}^{3}$ de madeira foi expresso em kcal, multiplicando-se a massa seca da madeira $(\mathrm{kg})$ pelo respectivo poder calorífico superior de cada espécie. Para conversão da energia de kcal. $\mathrm{kg}^{-1}$ para $\mathrm{kW} . \mathrm{h}$, dividiu-se o valor obtido em kcal.kg-1 por 860, obtendo para cada espécie, a energia produzida (kW.h) por metro cúbico de madeira (kW.h.m ${ }^{-3}$ ).

Para obter o estoque energético por hectare, multiplicou-se a energia produzida por metro cúbico de madeira $\left(\mathrm{kW} . \mathrm{h} / \mathrm{m}^{3}\right)$ pela produtividade média de cada espécie $\left(\mathrm{m}^{3} \cdot \mathrm{ha}^{-1}\right)$, obtendo-se a produção energética em kW.h.ha ${ }^{-1}$.

\section{Análise estatística}

$\mathrm{O}$ experimento foi analisado segundo um delineamento inteiramente casualizado, com oito tratamentos (espécies), com quatro repetições (árvores-amostra), totalizando 32 unidades amostrais.

Os dados foram submetidos aos testes de Lilliefors para testar a normalidade, e Cochran para testar a homogeneidade das variâncias. Em seguida, procedeu-se à análise de variância pelo teste $F$, sendo as médias comparadas pelo teste Tukey. Para as variáveis que não apresentaram homogeneidade das variâncias, foi aplicado o teste não paramétrico de Kruskall-Wallis. Considerou-se sempre o nível de significância de $5 \%$. As análises estatísticas foram realizadas com o auxílio do programa STATISTICA 8.0 (STATSOFT, INC, 2009).

\section{RESULTADOS E DISCUSSÃO}

As variáveis densidade básica, teor de enxofre (S) e energia gerada por cada espécie (kW.h.m ${ }^{-3}$ e kW.h.ha ${ }^{-1}$ ) não apresentaram homogeneidade das variâncias e foram submetidas ao teste não paramétrico de Kruskall-Wallis.

Para as demais variáveis analisadas, os tratamentos foram significativos pela análise de variância (teste $F$ ), a $5 \%$ de significância $(p<0,05)$, exceto para as variáveis $\mathrm{He} \mathrm{C} / \mathrm{H}(p>0,05)$. 
Os valores médios observados para a densidade básica das madeiras das oito espécies estão apresentados na Figura 1.

Pode-se observar na Figura 1, que a madeira de Mororó apresentou maiores valores médios de densidade $\left(0,97 \mathrm{~g} . \mathrm{cm}^{-3}\right)$, seguido da Jurema-preta $\left(0,90 \mathrm{~g} \cdot \mathrm{cm}^{-3}\right)$. Já os menores valores foram observados para as madeiras de Pereiro $\left(0,62 \mathrm{~g} \cdot \mathrm{cm}^{-3}\right) \mathrm{e}$ Imburana $\left(0,29 \mathrm{~g} \cdot \mathrm{cm}^{-3}\right)$. Isso evidencia a variabilidade existente entre as espécies, principalmente, no que se refere à importância da densidade básica, tanto em relação à quantidade de energia armazenada por unidade de volume quanto ao transporte e uso das mesmas.

Lima (2007) ao estudar a densidade básica de espécies em uma área do semiárido nordestino, no estado de PE, encontrou valores médios equivalentes a $0,68 \mathrm{~g} . \mathrm{cm}^{-3}$ para a madeira de Mororó, valor inferior ao obtido neste trabalho. $\mathrm{O}$ mesmo autor também estudou a madeira de Imburana e observou valores médios de $0,30 \mathrm{~g} . \mathrm{cm}^{-3}$ para densidade básica dessa espécie, bem próximos aos do presente trabalho.

Melo et al. (2006) ao estudarem a variação da densidade em madeiras do semiárido nordestino, no estado da PB, observaram, dentre as espécies comuns entre àquele e o presente trabalho, maiores valores médios para a madeira de Jurema-preta $\left(0,99 \mathrm{~g} \cdot \mathrm{cm}^{-3}\right)$ e menores valores para o Marmeleiro $\left(0,68 \mathrm{~g}_{\mathrm{cm}} \mathrm{cm}^{-3}\right)$. Araújo et al. (2004) estudando um povoamento de Jurema-preta na mesma área encontraram valores médios de $0,77 \mathrm{~g} . \mathrm{cm}^{-3}$. Esses autores referem que o valor encontrado é inferior ao observado por Zákia et al. (1992) para a mesma espécie, na região do Seridó, no Rio Grande do Norte, que foi de $0,86 \mathrm{~g} . \mathrm{cm}^{-3}$.

Melo et al. (2007), ao avaliarem a densidade básica da madeira de Pereiro, encontraram valores médios equivalentes a $0,79 \mathrm{~g} . \mathrm{cm}^{-3}$, superiores aos observados nesse trabalho.

Maiores valores também foram observados por Carvalho (2009), quando comparado aos do presente trabalho, para a densidade básica da madeira de Imburana $\left(0,43 \mathrm{~g} . \mathrm{cm}^{-3}\right)$. No entanto, são valores inferiores aos observados por Barros (2009) ao estudar essa espécie visando à fonte energética no semiárido nordestino, o qual encontrou valores equivalentes a $0,60 \mathrm{~g} . \mathrm{cm}^{-3}$. O autor concluiu que a Imburana obteve um desempenho inferior, quando comparada às outras espécies estudadas, dentre elas a Jurema-preta $\left(0,93 \mathrm{~g} . \mathrm{cm}^{-3}\right)$, sendo a madeira mais leve e menos densa isoladamente. Isso revela que essa espécie não é recomendada para a geração de energia, visto que seria necessário maior demanda de madeira para uma mesma produção.

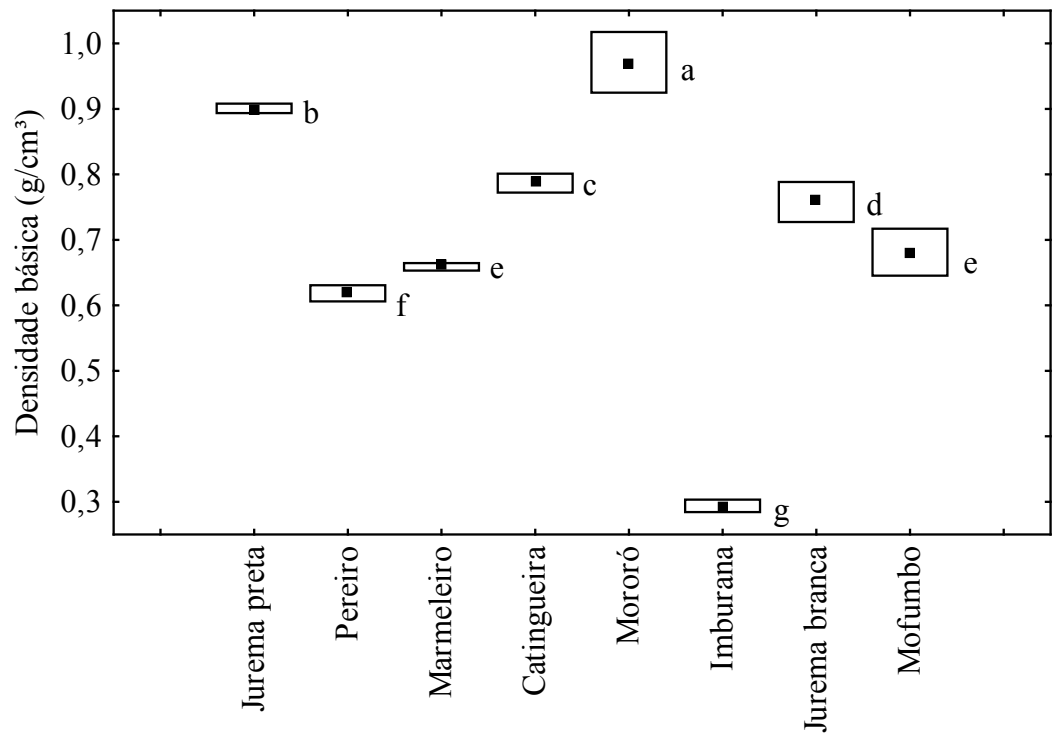

Espécie

Médias seguidas da mesma letra entre as espécies, não diferem entre si, a 5 \% de significância, pelo teste Kruskall-Wallis.

FIGURA 1: Valores médios para densidade básica da madeira das oito espécies estudadas.

FIGURE 1: Mean values for wood density of eight species studied. 
Santos (2010), estudando a qualidade da madeira para produção de energia em plantios comerciais de clones de eucalipto, no estado de MG, observou, para o clone com melhor desempenho energético, valor médio para a densidade básica equivalente a $0,55 \mathrm{~g} \cdot \mathrm{cm}^{-3}$.

Provavelmente, as diferenças observadas entre os valores médios para a densidade básica da madeira entre os referidos trabalhos, ocorreram em razão da diferença de sítio e da idade das plantas amostradas. Além disso, deve-se considerar que outros fatores colaboram para variação dessa propriedade entre espécies, e até entre árvores de uma mesma espécie, e mesmo dentro da própria árvore, como àqueles relacionados ao genótipo, localização geográfica, tratos silviculturais, métodos de amostragem, entre outros (PANSHIN e ZEEWUN, 1982).

Considerando o estudo da potencialidade

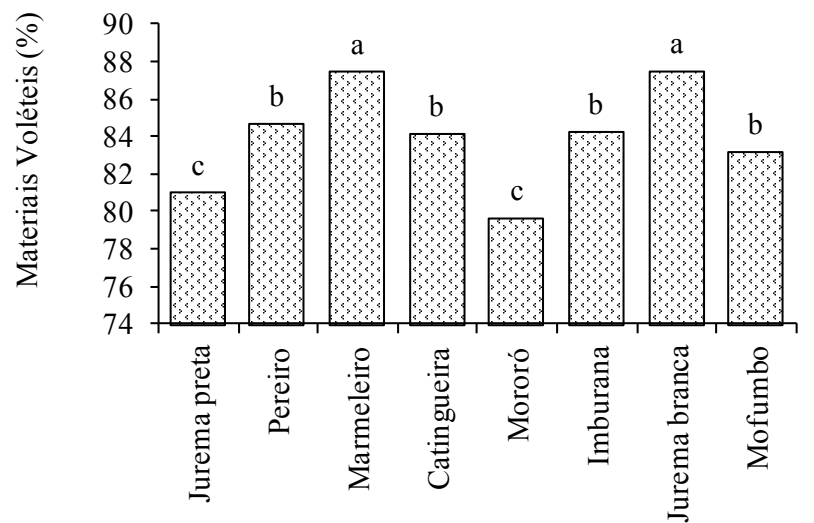

Espécie

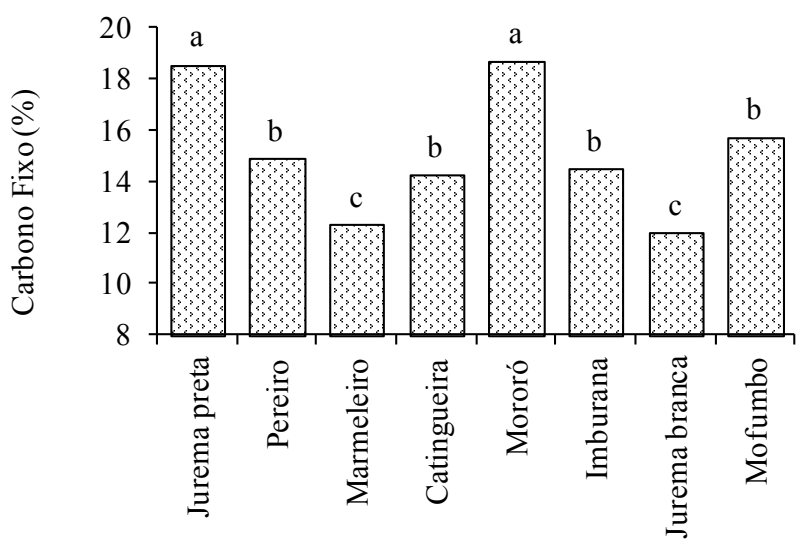

Espécie energética da madeira, a densidade básica é considerada um índice de qualidade importante, pois, quanto maior a densidade da madeira, maior será seu desempenho energético, seja na queima direta ou em processos de transformação. Assim, maior será a massa por volume a ser convertida em energia. Também algumas vantagens são observadas no produto originado dos processos de transformação, como é o caso do carvão vegetal originado de madeiras mais densas, o qual possui, de modo geral, maior resistência mecânica, entre outras vantagens.

No entanto, vale ressaltar que, em função da alta correlação com outras propriedades da madeira, a densidade básica não deve ser utilizada como índice isolado de qualidade.

Os valores médios para a análise química imediata e o poder calorífico superior da madeira das oito espécies são apresentados na Figura 2.

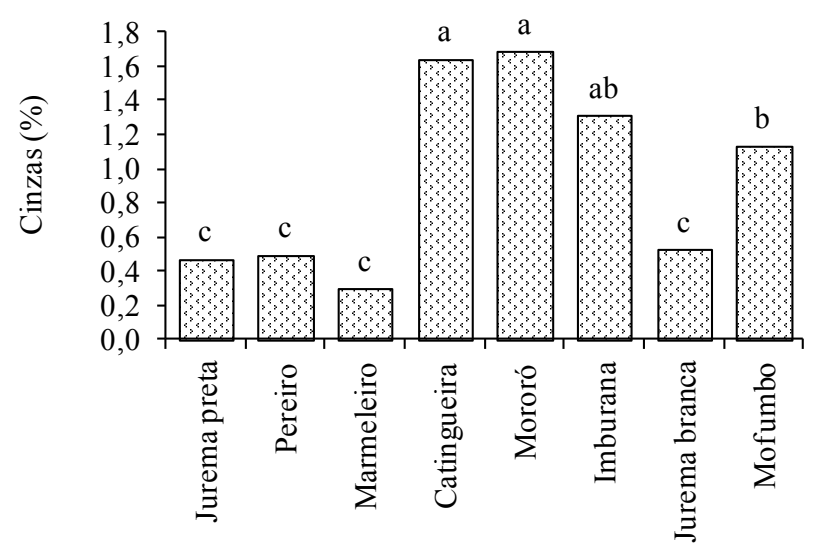

Espécie

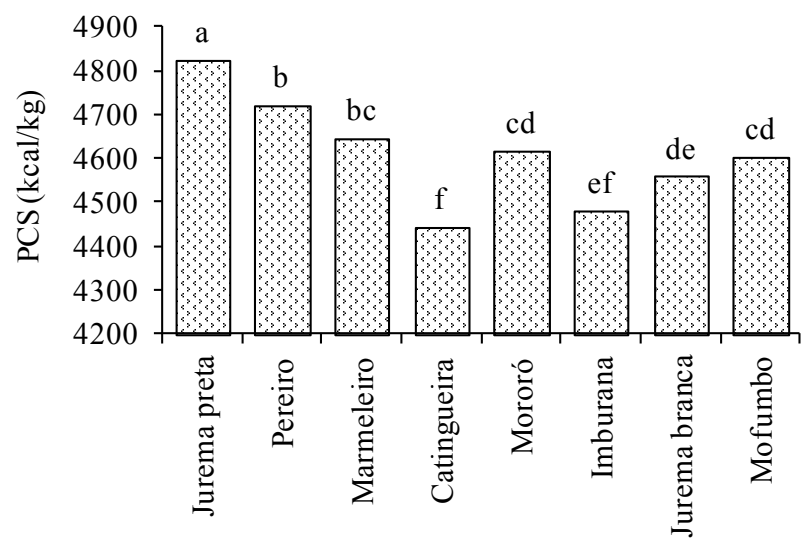

Espécie

Médias seguidas da mesma letra entre as espécies, para uma mesma variável, não diferem entre si, a $5 \%$ de significância, pelo teste Tukey.

FIGURA 2: Valores médios para as variáveis: Materiais Voláteis (\%); Cinzas (\%); Carbono Fixo (\%) e PCS $(\mathrm{kcal} / \mathrm{kg})$ observados nas madeiras das oito espécies.

FIGURE 2: Mean values for the variables: Volatile Material (\%); Ash (\%); Fixed Carbon (\%) and HHV ( $\mathrm{kcal} / \mathrm{kg}$ ) observed in eight wood species. 
Observa-se na Figura 2 que as espécies Jurema-branca e Marmeleiro foram as que apresentaram maiores valores médios significativos em $5 \%$ de significância para os teores de materiais voláteis na madeira, $87,52 \%$ e $87,44 \%$, respectivamente, os quais não diferiram entre si. Já a Jurema-preta e o Mororó apresentaram os menores valores, $80,98 \%$ e $79,64 \%$, respectivamente, e também não apresentaram diferença significativa entre si. Consequentemente, por serem variáveis inversamente proporcionais, as madeiras das espécies Jurema-branca e Marmeleiro apresentaram menores valores para o teor de carbono fixo (12,26 \% Jurema-branca) e (11,95 \% - Marmeleiro), enquanto que a Jurema-preta e o Mororó apresentaram, respectivamente, os maiores valores $(18,54 \%$ e 18,67$)$.

Os resultados observados diferem daqueles encontrados por Brito e Barrichelo (2006) ao estudarem as características de oito espécies de eucalipto como combustíveis, os quais encontraram valores que variaram entre $74,1 \%$ e $89,9 \%$, para o teor de materiais voláteis, e entre $9,6 \%$ e $24,3 \%$, para a porcentagem de carbono fixo presentes na madeira.

Os valores obtidos por meio da análise química imediata da madeira são importantes, principalmente quando se faz a queima direta da madeira (combustão), pois essas variáveis afetam a velocidade de queima, bem com a homogeneidade da chama na câmara de combustão, por influenciar as fases da reação de oxidação. A porcentagem de materiais voláteis na madeira expressa a sua queima no estado gasoso e esses são compostos, principalmente, de hidrogênio, hidrocarbonetos, $\mathrm{CO}$ e $\mathrm{CO}_{2}$. Por outro lado, o teor de carbono fixo expressa sua queima no estado sólido e é responsável pela formação da massa amorfa. Assim, conforme mencionado anteriormente, a proporção entre esses parâmetros irá influenciar características importantes, como o tempo e as fases da reação, em razão dos componentes voláteis, quando aquecidos, saírem do material e se queimarem rapidamente na forma gasosa, e o carbono fixo, queimar-se vagarosamente na fase sólida como resíduo.

De acordo com Smith (1976), citado por Brito e Barrichelo (2006), materiais combustíveis que apresentam altos teores de materiais voláteis são mais fáceis de serem oxidados e queimam mais rapidamente.

Ainda na Figura 2, observa-se o teor de cinzas presente na madeira das oito espécies, sendo os maiores valores obtidos para as madeiras de Mororó $(1,68 \%)$, Catingueira (1,64 \%) e Imburana (1,3\%), os quais não apresentam diferenças significativas entre si em $5 \%$ de significância. Vale salientar que o teor de cinzas afeta negativamente o poder calorífico da madeira. Assim, verifica-se também que essas espécies apresentaram, de modo geral, os menores valores médios de poder calorífico superior.

Oliveira (2003) ao estudar as características químicas e térmicas da madeira de três espécies de maior ocorrência no semiárido nordestino observou teor de cinzas equivalentes a $0,68 \%$ para o Marmeleiro e 0,56\% para as madeiras de Jurema-preta e Pereiro. Esses valores diferem dos encontrados no presente trabalho os quais equivalem a $0,29 \%, 0,46 \%$ e $0,49 \%$, para essas espécies, respectivamente.

Avaliando o poder calorífico superior das diferentes espécies, observa-se que a madeira de Jurema-preta obteve o maior valor médio (4.823 kcal $/ \mathrm{kg})$, diferindo significativamente das demais. Os menores valores foram observados para Catingueira $(4.442 \mathrm{kcal} / \mathrm{kg})$ que não diferiu da madeira de Imburana $(4.478 \mathrm{kcal} / \mathrm{kg})$.

Oliveira (2003) encontrou valores médios de poder calorífico superior da madeira, inferiores aos obtidos nesse trabalho, para as espécies Juremapreta $(4.482 \mathrm{kcal} / \mathrm{kg})$, Pereiro $(4.431 \mathrm{kcal} / \mathrm{kg})$ e Marmeleiro $(4.388 \mathrm{kcal} / \mathrm{kg})$. O mesmo foi observado para os valores encontrados por Lima (1996) para as madeiras de Jurema-preta e Pereiro para as quais foram determinados valores equivalentes a $4.150 \mathrm{kcal} / \mathrm{kg}$ e $4.062 \mathrm{kcal} / \mathrm{kg}$. No entanto, o mesmo autor encontrou para a madeira de Algaroba, muito utilizada na região nordeste como fonte energética, valores médios superiores aos observados para Jurema-preta e equivalentes a $4.954 \mathrm{kcal} / \mathrm{kg}$.

A quantidade de calor desprendida da madeira é muito importante para conhecer a capacidade energética de uma determinada espécie. Santos (2010) refere que essa característica é influenciada por outros fatores, como a composição química imediata da madeira, especialmente as porcentagens de carbono fixo e cinzas, entre outros.

Essa inferência pode ser percebida nos maiores valores observados para o teor de carbono fixo presente na madeira de Jurema-preta e menores porcentagens de cinzas, na medida em que apresentou também o maior PCS. O Mororó apesar de não ter apresentado a diferença significativa da Juremapreta para altos teores de carbono fixo, apresentou maiores porcentagens de cinzas na madeira, que, possivelmente, reduziu a energia desprendida durante a combustão completa da madeira dessa espécie. 
Os valores médios para a análise química elementar e as relações $\mathrm{C} / \mathrm{H}$ e $\mathrm{C} / \mathrm{N}$ observados nas madeiras são mostrados na Figura 3. Na Figura 4 estão apresentados os valores médios para o teor de enxofre.

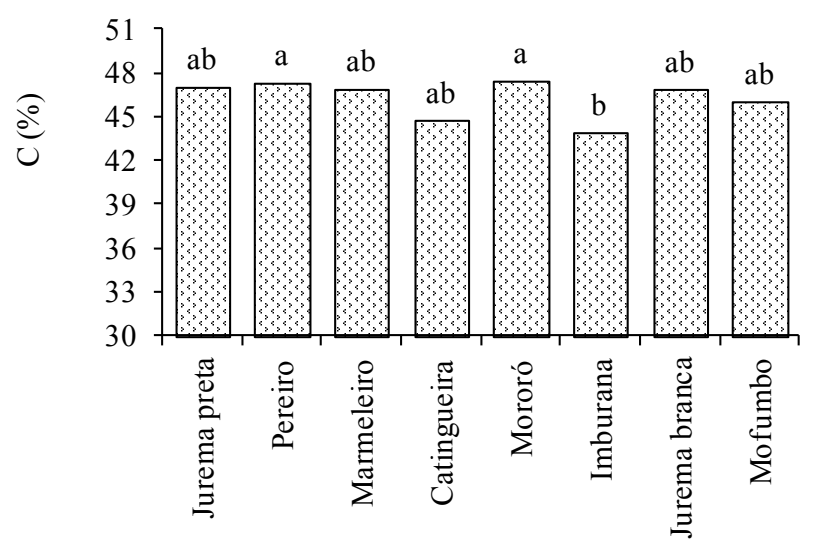

Espécie

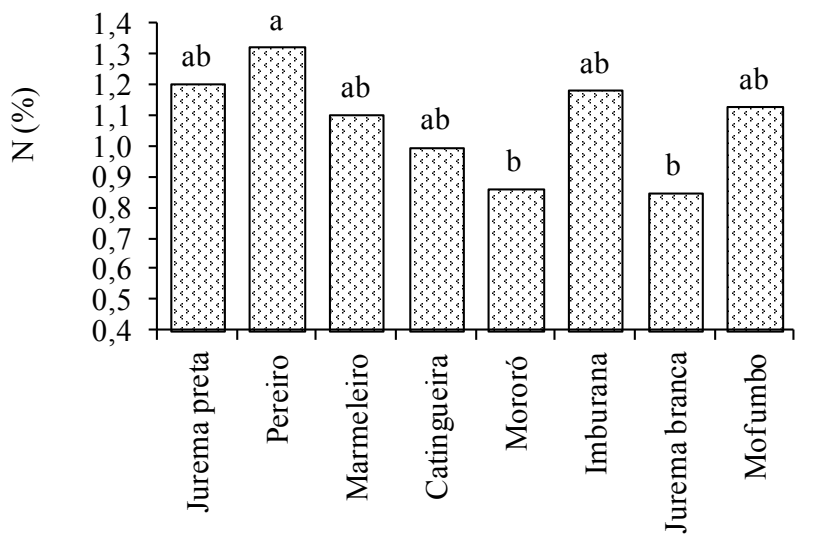

Espécie

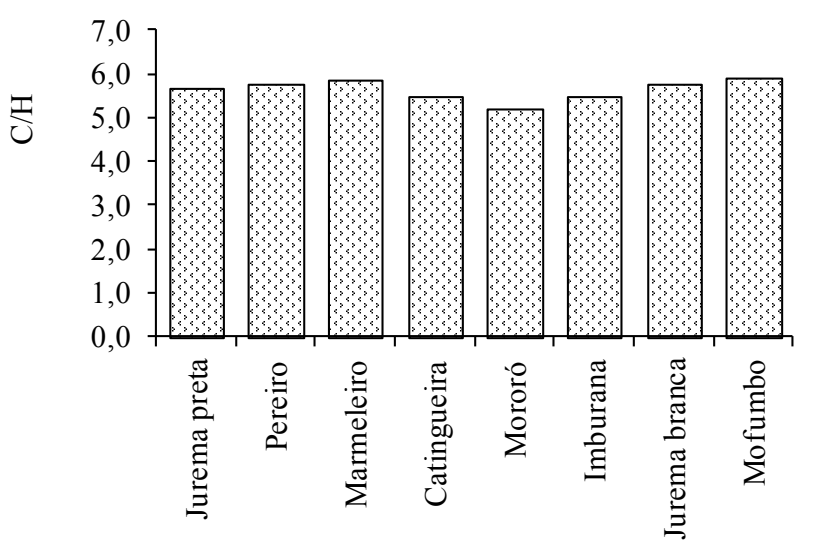

Espécie
Foi observado efeito da espécie nos teores de carbono (C). Os maiores valores foram obtidos para as madeiras de Mororó (47,23\%) e Pereiro $(47,24 \%)$, as quais não diferem entre si a $5 \%$ de significância, e os menores teores foram observa-

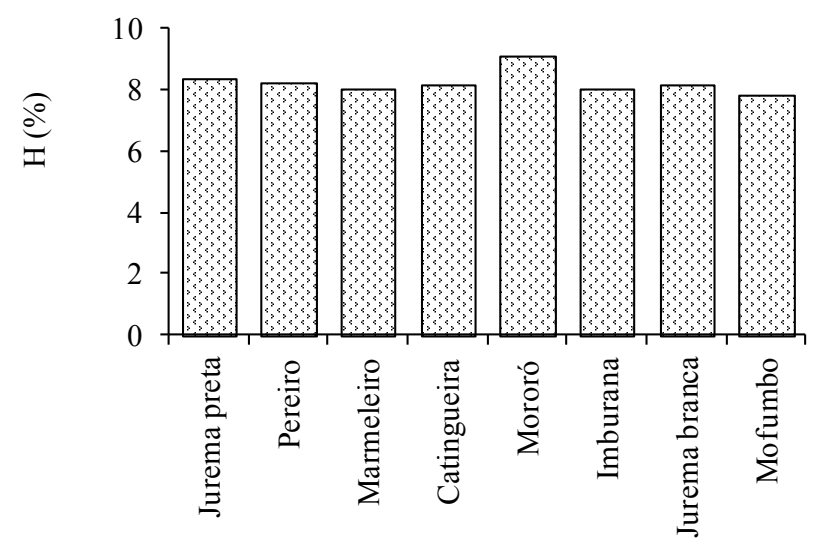

Espécie

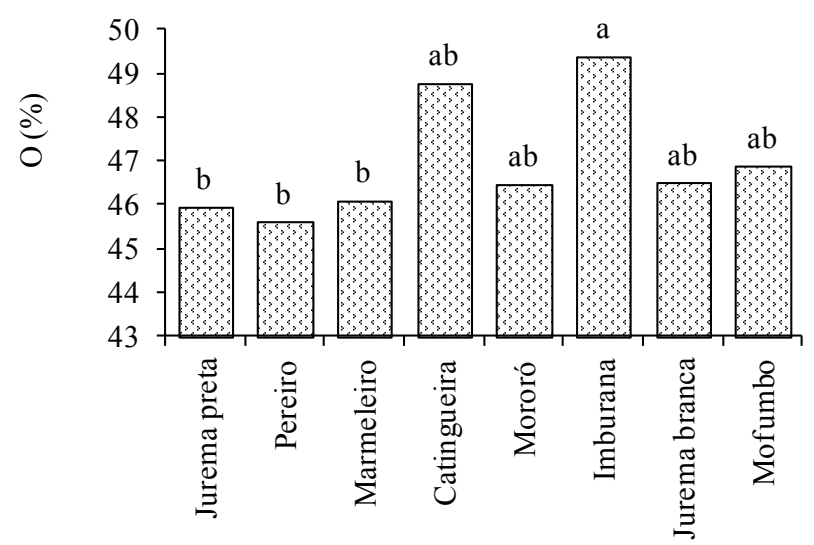

Espécie

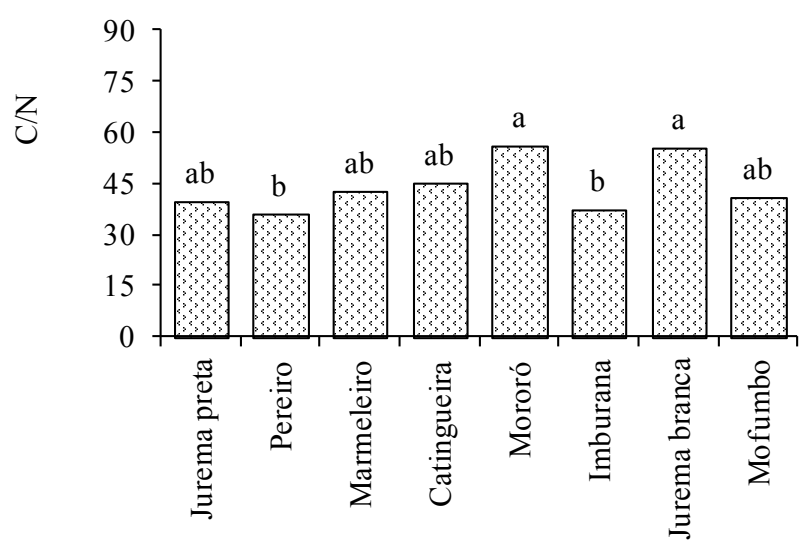

Espécie

Médias seguidas da mesma letra entre as espécies, para uma mesma variável, não diferem entre si, a $5 \%$ de significância, pelo teste Tukey.

FIGURA 3: Valores médios para as variáveis C (\%), $\mathrm{H}(\%), \mathrm{N}(\%), \mathrm{O}(\%)$, relação $\mathrm{C} / \mathrm{N}$ e relação $\mathrm{C} / \mathrm{H}$ para oito espécies da caatinga.

FIGURE 3: Mean values for the variables $\mathrm{C}(\%), \mathrm{H}(\%), \mathrm{N}(\%), \mathrm{O}(\%), \mathrm{C} / \mathrm{N}$ and $\mathrm{C} / \mathrm{H}$ for the eight caatinga species. 


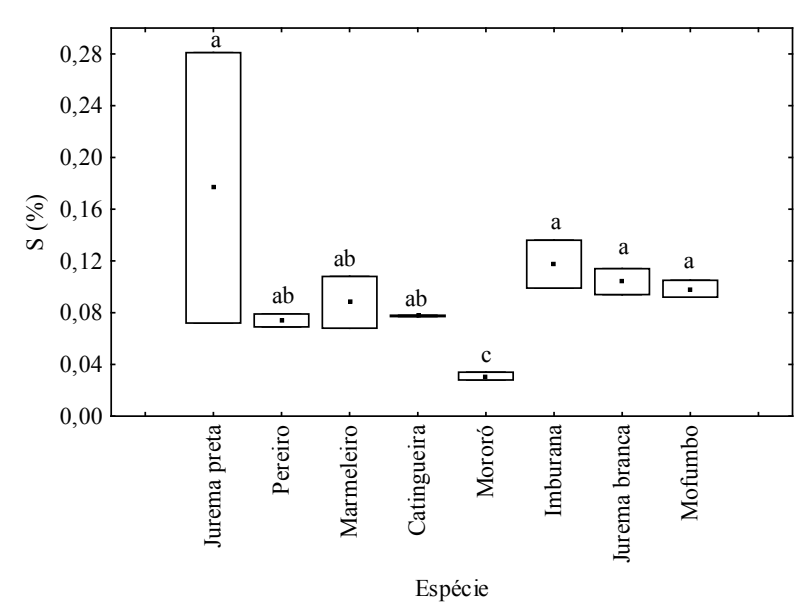

Médias seguidas da mesma letra entre as espécies, para uma mesma variável, não diferem entre si, a $5 \%$ de significância, pelo teste Kruskall-Wallis.

FIGURA 4: Valores médios para os teores de S (\%) observados na madeira das espécies analisadas.

FIGURE 4: Mean values for S (\%) concentrations observed in the Wood studied species.

dos para Imburana $(43,85 \%)$, sendo esse significativamente diferente.

Para o teor de nitrogênio $(\mathrm{N})$, os maiores valores foram observados para Pereiro $(1,32 \%)$, os quais diferem dos obtidos nas madeiras de Juremabranca $(0,84 \%)$ e Mororó $(0,86 \%)$.

Maiores valores significativos para os teores de oxigênio $(\mathrm{O})$ foram observados para Imburana $(49,37 \%)$ os quais diferem daqueles observados para os menores valores, estatisticamente iguais entre si, encontrados para Marmeleiro $(46,09 \%)$, Pereiro $(45,60 \%)$ e Jurema-preta $(45,93 \%)$.

No estudo da relação carbono/nitrogênio $(\mathrm{C} / \mathrm{N})$, maiores valores foram observados para as madeiras de Mororó (56 \%) e Jurema-branca $(55,41 \%)$, sendo esses significativamente iguais, os quais diferem dos menores teores obtidos para Pereiro $(35,79 \%)$ e Imburana $(37,28 \%)$, também sem diferença significativa entre si.

Os teores de enxofre (S) presentes nas madeiras das diferentes espécies não apresentaram grandes diferenças entre si, exceto para a espécie Mororó $(0,03 \%)$, sendo os maiores valores observados para Jurema-preta $(0,17 \%)$.

Mesmo a madeira sendo um combustível com baixa porcentagem de enxofre, menores porcentagens sempre são desejadas, evitando assim a formação e emissão de gases sulfurosos para atmosfera.

Não foi observado efeito da espécie para as variáveis teor de hidrogênio $(\mathrm{H})$ e relação carbono/ hidrogênio $(\mathrm{C} / \mathrm{H})$.

Arantes (2009) ao determinar a variabilidade existente nas características da madeira de um híbrido de eucalipto utilizado como fonte de energia encontrou valores médios para $\mathrm{C}, \mathrm{N}, \mathrm{O}$ e $\mathrm{H}$ equivalentes a $49,67 \% ; 0,18 \% ; 43,77 \%$ e $6,34 \%$, respectivamente. Barros (2009) ao estudar espécies do semiárido nordestino, no estado de $\mathrm{PE}$, encontrou valores médios para o teor de carbono equivalentes a $46,88 \%$ para Jurema-preta e $44,98 \%$ para Imburana.

De modo geral, espera-se que madeiras com maiores teores de carbono possuam relação positiva com maior resistência térmica, e consequentemente, fornecimento de energia por mais tempo, devido à natureza química desse elemento. No entanto, deve-se ressaltar que o H é o elemento químico com maior capacidade de fornecer energia a partir da combustão da madeira. De acordo com a UFMG (2010), a grande maioria dos combustíveis, excetuando-se os nucleares, depende do efeito térmico resultante da combustão do carbono e hidrogênio. Já a presença de oxigênio na madeira oferece a desvantagem de diminuir seu valor como combustível.

Ainda considerando-se a utilização da madeira como fonte secundária de energia, deve-se ressaltar que, de acordo com Penedo (1980), da porcentagem de carbono presente na madeira, boa parte desse elemento reage com o hidrogênio e com o oxigênio quando submetido ao processo de carbonização, ocorrendo a volatilização do mesmo e consequente formação de gases não condensáveis e também gases condensáveis. Assim, somente uma fração pode ser considerada como carbono fixo que é estável e não se decompõe sob atmosferas inertes.

Nas Figuras 5 (A) e (B) são mostrados os valores médios da energia produzida pelas espécies em kW.h.m ${ }^{-3}$ e kW.h.ha ${ }^{-1}$, respectivamente.

Conforme observado na Figura 5 (A) o Mororó e a Jurema-preta foram as espécies com maior produção de energia por $\mathrm{m}^{3}$ equivalentes, respectivamente, a 5.214 kW.h.m ${ }^{-3}$ e 5.052 kW.h.m. ${ }^{-3}$.

A produção de energia observada por hectare foi maior para as espécies Jurema-preta (29.635 kW.h.ha-1) e Pereiro (8.008 kW.h.ha' ${ }^{-1}$ ). Esses resultados estão diretamente relacionados à densidade básica, como também à produtividade 
volumétrica e ao poder calorífico de cada espécie e auxiliam na tomada de decisão em relação à utilização da floresta nativa manejada no que se refere à exploração para fins energéticos, visto que não basta apenas a espécie apresentar características tecnológicas favoráveis à produção de energia, mas, também, deve-se considerar sua produtividade por hectare.

(A)

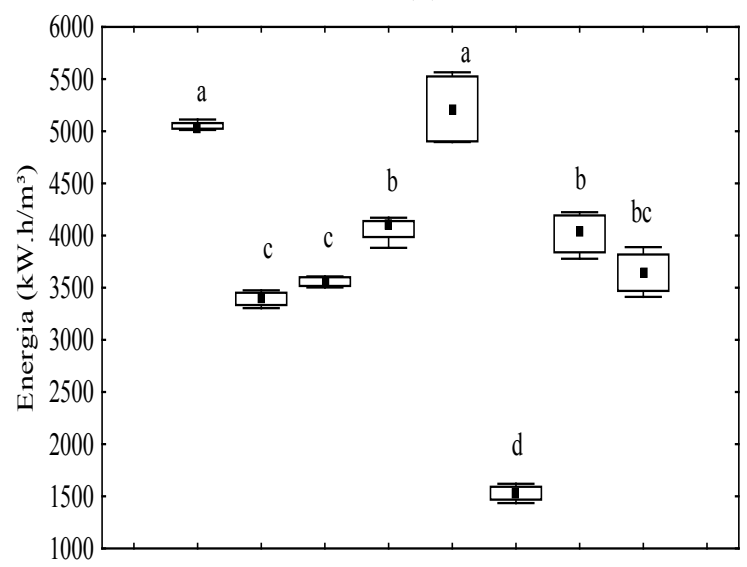

(B)

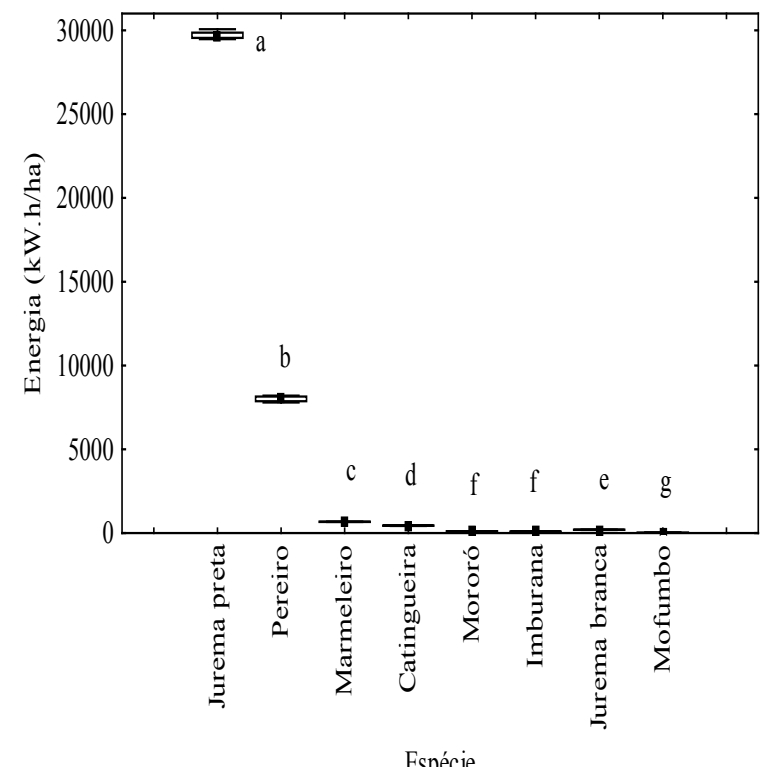

Médias seguidas da mesma letra entre as espécies, para uma mesma variável, não diferem entre si, a $5 \%$ de significância, pelo teste Kruskall-Wallis.

FIGURA 5: Energia produzida, em kW.h.m ${ }^{-3}$ (A) e em kW.h.ha-1 (B) pelas madeiras das oito espécies estudadas.

FIGURE 5: Energy produced in $\mathrm{kW} \cdot \mathrm{h} \cdot \mathrm{m}^{-3}$ (A) and kW.h.ha ${ }^{-1}$ (B) by the eight wood species.

\section{CONCLUSÕES E RECOMENDAÇÕES}

A madeira de Mororó possui alto potencial energético e proporciona economia, para uso energético, para uma mesma produtividade;

O Mororó possui alto potencial para ser utilizado como fonte secundária de energia, a exemplo da conversão em carvão vegetal;

O teor de cinzas na madeira de Mororó, provavelmente, colaborou para redução do poder calorífico superior dessa espécie;

A madeira de Mororó, apesar de apresentar boas características tecnológicas para produção de energia, apresenta baixa produtividade volumétrica;

A faixa de densidade básica observada para a madeira de Jurema-preta é considerada satisfatória quando se considera utilização da madeira para produção de energia, sendo indicada como potencial para produção de carvão vegetal;

A madeira de Pereiro se destaca, juntamente com a Jurema-preta, como potencial na produção de energia devido a sua maior produtividade;

A madeira de Imburana apresentou baixo potencial energético quando comparada às demais, não sendo, dessa maneira, recomendada para a geração de energia, pois seria necessário uma maior demanda de madeira para uma mesma produção;

As madeiras de Jurema-branca e Marmeleiro apresentam alto potencial energético como fonte primária de energia por meio da queima direta;

Provavelmente, a queima das madeiras de Jurema-branca e Marmeleiro se processa de forma rápida e com maior formação de chama. No outro extremo, espera-se para as madeiras de Juremapreta e Mororó que a queima dessas seja de modo mais lento e com menor formação de chama que as demais;

Para as madeiras com altas porcentagens de materiais voláteis, a exemplo da Jurema-branca e Marmeleiro, recomendam-se outras utilizações energéticas como a gaseificação para uso em motores estacionários;

O Pereiro, apesar de não se destacar em termos energéticos, apresenta alta produtividade volumétrica, proporcionando, juntamente com a Jurema-preta, alta produção de energia por hectare;

Caso se pretenda manejar a área estudada, visando à produção de energia da madeira, a espécie que apresentou melhor desempenho energético foi a Jurema-preta, seguida da madeira de Pereiro. No entanto, se o objetivo for selecionar a espécie que mais produz energia por $\mathrm{m}^{3}$ os melhores resultados 
foram observados para as madeiras de Jurema-preta e Mororó;

A densidade básica, a produtividade volumétrica e o poder calorífico das espécies são variáveis imprescindíveis na indicação de espécies potenciais para uso energético.

\section{REFERÊNCIAS BIBLIOGRÁFICAS}

ABNT - ASSOCIAÇÃO BRASILEIRA DE NORMAS TÉCNICAS. NBR 6923:1981 Carvão vegetal - Amostragem e preparação da amostra. Rio de Janeiro: ABNT, 1981. 15 p.

ABNT - ASSOCIAÇÃO BRASILEIRA DE NORMAS TÉCNICAS. NBR 8112:1986 Carvão vegetal - Análise imediata. Rio de Janeiro: ABNT, 1986. 5 p.

ABNT - ASSOCIAÇÃO BRASILEIRA DE NORMAS TÉCNICAS. NBR 8633:1984 Carvão vegetal - Determinação do poder calorífico. Rio de Janeiro: ABNT, 1986. 13 p.

ANA - Agência Nacional das Águas. Programa de Desenvolvimento Sustentável e Convivência com o Semi-Árido Potiguar: Relatório de Avaliação Ambiental (RAA). Secretaria de Estado de Recursos Hídricos, 2005. Rio Grande do Norte, N. 4310/BR, 2005. 132 p.

ARANTES, M. D. C. Variação nas características da madeira e do carvão vegetal de um híbrido de Eucalyptus grandis W.Hill ex Maiden $x$ Eucalyptus urophylla S. T. Blake. 2009. 158 p. Tese (Doutorado em Ciência e Tecnologia da Madeira) Universidade Federal de Lavras, Lavras, 2009.

ARAÚJO, L. V. C. et al. Estimativa da produção de biomassa de um povoamento de Jurema-Preta (Mimosa tenuiflora (WILLD.) POIRET. com cinco anos de idade. Revista Biomassa \& Energia, Dourados, v. 1, n. 4. p. 347-352, out./dez, 2004.

BARROS, B. C. Volumetria, calorimetria e fixação de carbono em florestas plantadas com espécies exóticas e nativas usadas como fonte energética no polo gesseiro do Araripe-PE. 2009. 63 f. Dissertação (Mestrado em Ciência Florestal) Universidade Federal Rural de Pernambuco, Recife, 2009.

BRITO, J. O.; BARRICHELO, L. E. G. Comportamento isolados da lignina e da celulose da madeira frente à carbonização. Piracicaba: ESALQ, 2006. 4 p. (Circular Técnica, 28).

CARVALHO, P. E. R.; Imburana-de-Espinho. Colombro/ PR. 2009. (Comunicado Técnico, 228). Disponível em: <http://www.demec.ufmg.br/ disciplinas/ema003/solidos/madeira/madeira.htm>. Disponível em: <(ftp://geoftp.ibge.gov.br/mapas/ tematicos/mapas_murais) $>$ Acesso em: 02 de junho de 2010.

IBGE-Instituto Brasileiro de Geografia e Estatística. Mapa de clima do Brasil, 2002. Disponível em: $<$ (ftp://geoftp.ibge.gov.br/mapas/tematicos/mapas murais) $>$ Acesso em: 24 de junho de 2010.

IBGE-Instituto Brasileiro de Geografia e Estatística. Mapa de solos do Brasil, 2001. Disponível em: $<$ (ftp://geoftp.ibge.gov.br/mapas/tematicos/mapas murais) $>$ Acesso em: 02 de maio de 2010.

IBGE - Instituto Brasileiro de Geografia e Estatística. Mapa de unidades de relevo do Brasil, 2006.

IBGE - Instituto Brasileiro de Geografia e Estatística. Mapa de vegetação do Brasil, 2004. Disponível em: <(ftp://geoftp.ibge.gov.br/mapas/ tematicos/mapas murais) $>$ Acesso em: 20 de junho de 2010.

LIMA, A. L. A. Padrões fenológicos de espécies lenhosas e cactáceas em uma área do semi-árido do Nordeste brasileiro. 2007, 71 f. Dissertação (Mestrado em Botânica) - Universidade Federal Rural de Pernambuco, Recife, 2007.

LIMA, J. L. S. Características físico-mecânicas e energéticas de madeiras do trópico semi-árido do Nordeste do Brasil. Boletim de pesquisa. EMBRAPA/CPATSA, n. 63, p.1-12, 1996.

MELO, R. R. et al. Estudo da variação radial da densidade básica de sete madeiras do semi-árido. Revista Científica Eletrônica de Engenharia Florestal, Garça, n. 7. p. 347-352, fev./ago, 2006.

MELO, R. R. et al. Variação radial da massa específica da madeira de seis espécies florestais. In: ENCONTRO DE PÓS-GRADUAÇÃO, 9., 2007, Pelotas. Anais... Pelotas: Universidade Federal de Pelotas, 2007. v. 9. p. 1273-1278.

OLIVEIRA, E. Características anatômicas, químicas e térmicas da madeira de três espécies de maior ocorrência no semi-árido nordestino. 2003. 122 p. Tese (Doutorado em Ciências Florestais) - Universidade Federal de Viçosa, Viçosa, 2003.

PANSHIN, A. J.; ZEEUW, C.de. Textbook of wood tecnology. $4^{\text {th }}$ ed. New York. McGraw Hill, 1988. $722 \mathrm{p}$.

PENEDO, W. R. Uso da madeira para fins energéticos. Belo Horizonte: CETEC, 1980. 49 p. SANTOS, R. C. dos. Parâmetros de qualidade da madeira e do carvão vegetal de clones de eucalipto. 2010. 122 p. Tese (Doutorado em Ciência 
e Tecnologia da Madeira) - Universidade Federal de Lavras, Lavras, 2010.

STATSOFT, Inc. STATISTICA (data analysis software system), version 8. 2009. (Software Estatístico).

UFMG - Universidade Federal de Minas Gerais. Departamento de Engenharia Mecânica. Combustíveis sólidos: madeira. Belo Horizonte, 2010.
VITAL, B. R. Métodos de determinação da densidade da Madeira. Viçosa: SIF, 1984. 21 p. (SIF, Boletim Técnico,1).

ZÁKIA, M. J. B. et al. Equações de peso e de volume para oito espécies lenhosa nativas do Seridó, RN. In: IBAMA. Plano de manejo florestal para a região do Seridó do Rio Grande do Norte. Natal: PNUD / FAO / IBAMA - Governo do Rio Grande do Norte, 1992. p. 1-92. 